\title{
IMPACT OF VIDEO ANALYSIS OF MINI-HANDBAL GAMES ON CHILDREN TRAINING
}

\author{
Cezar HANTĂU ${ }^{1 *}$, Vladi IONESCU ${ }^{1}$, Athanasios YANNAKOS ${ }^{2}$, Narcis NEAGU $^{3}$ \\ ${ }^{1}$ National University of Physical Education and Sport, Faculty of Physical Education and Sport, \\ Bucharest, Romania \\ ${ }^{2}$ Aristotelis University, Thessaloniki, Greece \\ ${ }^{3}$ Politehnica University, Faculty of Medical Engineering, Bucharest, Romania \\ *Corresponding author: hantau.cezar@gmail.com
}

https://doi.org/10.35189/dpeskj.2020.59.4.7

\begin{abstract}
When we talk about mini-handball, we are thinking of a group of children playing and having fun. Therefore, when talking about video analysis of mini-handball games, it may seem a little exaggerated. However, if we think that mini-handball is the first stage of handball training, we realise that, in fact, the training is at the basic level. Video analysis of the games at this level is not for the purpose of analysing the own team game or the game of the opposing team to increase the sports performance of children. Instead, the purpose of video analysis at this level is to observe the most commonly used technical elements, technical procedures and tactical actions. All these observations will be used to optimise the training process, eliminate many unnecessary means used during training and create a training programme for this level. Our research was carried out after analysing a number of 124 mini-handball games played by four teams from Romania and Greece, after which we tried to create a mini-handball game model. Based on this game model, we will propose a training programme model adapted to this level of training. The training models allow the design of an effective training programme, which in turn allows us to rationally use the time allocated to the team training, to focus on the preponderant actions during the game and carry out training sessions adapted to the needs of the competition.
\end{abstract}

Keywords: mini-handball, video analysis, model, programme.

\section{Introduction}

Normally, when we talk about mini-handball, we are thinking of a group of children playing and having fun. Therefore, if we combine this image with the idea of video analysis, it might seem a little bit exaggerated. However, we can use video analysis at this stage, but the purpose is to observe the level reached by children in training and to know in which direction to channel our efforts in the training process.

Handball is one of the most popular sports worldwide. At present, according to data provided by the International Handball Federation, there are six continental confederations in the world with 209 countries, 795,000 clubs and approximately 19 million players. In addition, a very large number of people work in handball providing organizational support, training, health services, etc. and, as a result, lots of people are involved in world handball. The huge development of this sport has attracted the attention of many researchers and scientific journals addressing the field of Sports Science.

Reviewing the literature on the analysis of handball games, we notice that it has developed extraordinarily and that a large number of techniques and methods for analysing sports games have been established (Winkler \& Freibichler, 1991; Müller \& Lorenz, 1996). 
The systematic analysis of handball games, followed by the interpretation of the obtained data, began in France, on the occasion of the World Handball Championship in 1970 (KunstGhermănescu, 1976). Since then, a number of researchers have addressed this issue (Bilge, 2012; Czerwinski, 1998; Taborsky, 2000). Nowadays, video analysis of handball games is of great interest, especially for teams that work at the level of performance and high performance (Zapardiel Cortés et al., 2017).

An essential factor in interpreting the data obtained through video analysis is the impact that the coach has on the subsequent evolution of athletes. This is due to the storage of game variables, after which they are interpreted to evaluate sports performance. This evaluation has a key role in the subsequent planning of the training process (Gutiérrez et al., 2011). So, measuring performance is one of the main concerns of Sports Science (Bilge, 2012).

Published studies focusing on the analysis of handball games examined the performance of players from two points of view. On the one hand, most studies were based on recording the team actions during games and creating a set of data to reflect what happened in the game, regardless of how it happened. On the other hand, another group of studies (fewer in number) recorded the game actions in the chronological and sequential order, taking into account the context in which they were performed (Prieto et al., 2015).

In a broad sense, team games involve all kinds of very unpredictable situations. Thus, it is necessary to predict them as much as possible by developing game strategies. These strategies are possible based on the observation, recording, interpretation and analysis of collective behaviour. Therefore, coaches and researchers in the field use observation and game analysis to increase the level of training of athletes and enable them to react to surprising situations during games (Ferrari et al., 2018).

Based on the previous idea, we can say that the game of handball has a great variation and unpredictability of actions, because the two teams facing each other act as two nonlinear dynamic systems. Goal throws, the number of passes, a team's favourite tactical actions also include other indicators such as the effectiveness of goal throws and the effectiveness of attacks. Looking at things from this perspective, it is not easy to understand all the possibilities of action that can occur during a game. Therefore, relying on these data, performance models are designed that give us the directions for action in order to optimise and streamline the training of handball players (Saavedra et al., 2019).

Although various methods of analysis based on direct observation of games were used to objectify and streamline handball training, they have not proven their effectiveness because they highlight a very small number of variables. Therefore, it is necessary to use video systems and computer systems to highlight as many variables as possible, so that we have a more complex picture of what happens during a game (Zemkova \& Hamar, 2018).

To quantify what happens in the game, there are three types of methods: observational (from video recordings), physiological (monitoring body functions) and subjective (discussions with athletes). Quantitative analysis involves the digitisation of video images to allow the calculation of technical and tactical actions, this being possible even if minimal hardware and software are used. (Allinger, 1998)

Trout (2013) says that modelling based on video analysis is more efficient compared to traditional learning in order to make progress in motor learning. A study conducted by Sani and Khan (2018) shows that modelling is not only done in elite athletes but can also be used 
with remarkable results in novice athletes. Modelling is introduced at the level of beginners because their coaches are interested in designing a training programme to maximise the performance potential of these beginners for a later date (Morton, 1997).

Recent years have highlighted the existence of two main directions in the use of modelling. The first direction refers to the models that characterise the structure of competitive activities and the main aspects of athletic training. The second direction refers to the large structural units of the training process such as multiannual stages, preparation macrocycles, preparation stages or preparation microcycles. (Kostiukevych et al., 2018)

In the field of physical education and sports training, modelling is considered both a method and a principle. As a method, modelling is taken from the field of cybernetics. From the cybernetic point of view, modelling represents a specific method with precisely delimited rules and stages applicable to all fields of activity whose object of study are complex dynamic systems. Modelling involves developing a model. The model represents the mirroring of data and relationships in a certain field with the help of material (effective or hypothetical) structures, which are simpler and more easily noticeable.

In the field of sports training, we can discuss several types of models: final models, intermediate models, operational models, selection models, training models, competition models, player models. From our point of view, the game model specific to mini-handball is only an intermediate model until the achievement of the final game model - the game model of high performance. We say this based on the multi-year structure of handball training. Longterm training (Platonov, 1996) includes several stages, each one with intermediate objectives, which in fact pursue the ultimate goal, the achievement of great sports performance. The structure of the multiannual training should be developed taking into account several factors among which we mention: the average number of years necessary to reach maximum results; the age range at which athletes achieve these results; the individual qualities of athletes, as well as the pace of development of these qualities; the age at which athletes began to prepare and the age at which they switched to specific training.

Specialists from the former German countries (East Germany and West Germany) believed that multi-year training could be divided into four stages: psycho-motor training, specialised training, in-depth specialisation and high-performance training. Platonov (2004) considers that the multi-year training planning provides for five stages: the initial training stage; the stage of basic preliminary preparation; the specific preparation stage; the stage of preparation and obtaining maximum performance; the stage of maintaining the level reached. From the standpoint of the multiannual preparation for the handball game, we consider fair the division made by Platonov (2004), with the amendment that, instead of steps, we will use the term "stages", which is used in the training theory in Romania. Consequently, the stages of training in handball, from our point of view are:

1. The general preparation stage - includes children aged between $6 / 7$ and 10 years;

2. The sports training stage - includes children aged between 11 and 14 years;

3. The stage of specialised training - includes young people aged between 15 and 18 years;

4. The stage of obtaining maximum performance - includes athletes aged between 18 and 24 years;

5. The stage of maintaining the level reached - includes athletes over 24 years of age. 
These stages follow one another chronologically and it is very important to observe their limits, especially from the point of view of programming the training content and the required level of effort (Hantău, 2017).

\section{Purpose of study}

The purpose of this study is to compare the games played by four mini-handball teams based on the interpretation of data obtained from the video analysis of these games. Given that team A prepared and played according to the game model proposed by us, another purpose of this study is to validate this game model and this training model.

\section{Methodology}

In order to obtain the data necessary for the study, a number of 124 mini-handball games played by four teams from Romania and Greece were recorded. The video recordings were analysed using the "EIA" (efficiency in action) video analysis system. The children involved in these games are between 9 and 10 years old, most of them in the fourth year of training.

Among the methods used, we mention the method of bibliographic study to clarify our theoretical notions related to video analysis and modelling. We also took this step with the intention of seeing the current trends on these topics.

For the analysis of the obtained data, we also considered the complexity of the actions performed by players and the intensity of the opponents' opposition during the execution of these actions. Thus, we determined three types of complexity: $\mathrm{C} 1$ - technical-tactical actions performed on the spot at a convenient speed of movement; $\mathrm{C} 2$ - technical-tactical actions performed in motion with any spatiotemporal constraint; C3 - technical-tactical actions performed in motion and in direct combat with the opponent.

To reflect the players' activity, we used a set of five competition indicators, of which three indicators are quantitative (coefficient of intensity, coefficient of mobility and coefficient of aggression) and two are qualitative (coefficient of efficiency and coefficient of creativity).

Coefficient of intensity $(\mathrm{CI})$

$\mathrm{CI}=\frac{\mathrm{TA}}{\mathrm{t}}$

TA - the total number of technical-tactical actions of a player during the game; it is obtained by summing up the technical-tactical actions under $\mathrm{C} 1$ (TAC1) with those under C2 (TAC2) and those under C3 (TAC3).

$\mathrm{t}$ - the total time the player spent on the field.

Coefficient of mobility (CM)

$\mathrm{CM}=\frac{\mathrm{TAC} 2+\mathrm{TAC} 3}{\mathrm{t}} \times 2$

Coefficient of aggression (CA)

$\mathrm{CA}=\frac{\mathrm{TAC} 3}{\mathrm{t}} \times 3$

Coefficient of efficiency (CE)

$\mathrm{CE}=\frac{\mathrm{TA}}{\mathrm{TAC} 3}$

Coefficient of creativity (CC) 
$\mathrm{CC}=\frac{(\mathrm{NP} \times 1)+(\mathrm{NDP} \times 2)+(\mathrm{TG} \times 5)+(\mathrm{G} \times 10)}{\mathrm{t}}$

NP - number of passes; NDP - number of decisive passes; TG - throws on the goal area; G - number of goals

The integral evaluation (IE) of each team is performed by summing up the values of each calculated coefficient.

$$
\mathrm{IE}=\mathrm{CI}+\mathrm{CM}+\mathrm{CA}+\mathrm{CE}+\mathrm{CC}
$$

These five indicators were applied to the data recorded for each team. The actions recorded for the players of the four teams are: actions with the ball, passes, decisive passes, throws on the goal area, goals, offensive duels, defensive duels, interceptions. One of the four teams, team 1, was trained according to a training model proposed by us, and the games of this team took place according to a game model proposed by us. The other teams (team 2, team 3 and team 4 from Greece) trained and played according to the game and training models proposed by the coaches of these teams.

\section{Results}

\section{Proposed game and training model}

From the point of view of the training factors, their share in each year of training was the following (Table 1):

Table 1. The share of training components in the four years of training

\begin{tabular}{lccccc}
\hline & $\begin{array}{c}\text { Technical } \\
\text { preparation }\end{array}$ & $\begin{array}{c}\text { Tactical } \\
\text { preparation }\end{array}$ & $\begin{array}{c}\text { Physical } \\
\text { preparation }\end{array}$ & $\begin{array}{c}\text { Psychological } \\
\text { preparation }\end{array}$ & $\begin{array}{c}\text { Theoretical } \\
\text { Preparation }\end{array}$ \\
\hline Year I & $50 \%$ & $0 \%$ & $40 \%$ & $10 \%$ & $0 \%$ \\
Year II & $50 \%$ & $0 \%$ & $40 \%$ & $10 \%$ & $0 \%$ \\
Year III & $40 \%$ & $10 \%$ & $40 \%$ & $5 \%$ & $5 \%$ \\
Year IV & $40 \%$ & $10 \%$ & $40 \%$ & $5 \%$ & $5 \%$ \\
\hline
\end{tabular}

From the point of view of the preparation hours, assessment hours and games in which they participated, the situation is as follows (Table 2):

Table 2. Training hours, assessments and number of games

\begin{tabular}{lccccc}
\hline & Year I & Year II & Year III & Year IV & TOTAL \\
\hline No. of training sessions & 55 & 70 & 102 & 126 & 353 \\
Technical preparation (h) & 22.8 & 27.3 & 50 & 79.5 & 175 \\
Tactical preparation (h) & - & - & 12.5 & 19.5 & 32 \\
Physical preparation (h) & 26 & 38.4 & 50 & 79.5 & 194 \\
Psychological preparation (h) & 4.2 & 11 & 6.5 & 9.5 & 32 \\
Theoretical preparation (h) & - & - & 6.5 & 9.5 & 16 \\
Assessments (h) & 3 & 3 & 6 & 8 & 20 \\
Instruction (h) & 56 & 70 & 137.5 & 223 & 492 \\
No. of games & - & - & 11 & 34 & 45 \\
\hline
\end{tabular}


As can be seen in the table above, physical, technical and psychological preparation are the training factors that are not missing in any year. Instead, tactical and theoretical preparation appears only in the third year of training because, in the training strategy, the idea of opponent appears only in the third year.

Another aspect that can be observed in Table 2 is that, from year to year, in quantitative terms, all indicators increase. The differences between the first two years are given only by the number of workouts. Instead, in the following years, the differences are given by the increase in the number of training sessions but also their duration. Thus, if in the first two years, there were 2 weekly workouts of 60 minutes, in the third year, there were 2 weekly workouts of 75 minutes each, and in the fourth year, there were 3 weekly workouts of 90 minutes each. Another characteristic of the training model in the first stage is given by the training content and the way in which the technical elements and tactical actions are introduced in the training. Table 3 shows the stage of training the technical elements according to the year of training. It is observed in the table that certain elements and technical processes disappear after a certain period. This does not mean that they will disappear from the training, but that they will be included in the training of other technical elements. 
Table 3. Scheduling the training of the elements according to the year of training

\begin{tabular}{|c|c|c|c|c|c|c|c|c|c|c|c|c|c|}
\hline \multirow[t]{2}{*}{ Elements } & \multirow[t]{2}{*}{ Procedure } & \multicolumn{3}{|c|}{ Year I } & \multicolumn{3}{|c|}{ Year II } & \multicolumn{3}{|c|}{ Year III } & \multicolumn{3}{|c|}{ Year IV } \\
\hline & & $\begin{array}{l}\text { Step } \\
\text { I }\end{array}$ & $\begin{array}{l}\text { Step } \\
\text { II }\end{array}$ & $\begin{array}{c}\text { Step } \\
\text { III }\end{array}$ & $\begin{array}{l}\text { Step } \\
\text { I }\end{array}$ & $\begin{array}{l}\text { Step } \\
\text { II }\end{array}$ & $\begin{array}{c}\text { Step } \\
\text { III }\end{array}$ & $\begin{array}{c}\text { Step } \\
\text { I }\end{array}$ & $\begin{array}{l}\text { Step } \\
\text { II }\end{array}$ & $\begin{array}{l}\text { Step } \\
\text { III }\end{array}$ & $\begin{array}{c}\text { Step } \\
\text { I }\end{array}$ & $\begin{array}{c}\text { Step } \\
\text { II }\end{array}$ & $\begin{array}{c}\text { Step } \\
\text { III }\end{array}$ \\
\hline Getting used to the & Transport & $\mathrm{X}$ & $\mathrm{X}$ & $\mathrm{X}$ & & & & & & & & & \\
\hline ball & Hand-to-hand transmission & $X$ & $X$ & $X$ & & & & & & & & & \\
\hline & Individual throws and catches & $X$ & $\mathrm{X}$ & $X$ & & & & & & & & & \\
\hline Field movement & $\begin{array}{l}\text { Running, stopping, turning, } \\
\text { lateral movement }\end{array}$ & $\mathrm{X}$ & $\mathrm{X}$ & $\mathrm{X}$ & $\mathrm{X}$ & $\mathrm{X}$ & $\mathrm{X}$ & $\mathrm{X}$ & & & & & \\
\hline Dribbling & Simple and multiple & & $X$ & $\mathrm{X}$ & $X$ & $X$ & $\mathrm{X}$ & & & & & & \\
\hline Holding the ball & With one or two hands & $\mathrm{X}$ & $\mathrm{X}$ & $\mathrm{X}$ & $\mathrm{X}$ & & & & & & & & \\
\hline Throwing the ball & With two hands & & & $\mathrm{X}$ & $\mathrm{X}$ & $\mathrm{X}$ & & & & & & & \\
\hline & With one hand & & & $\mathrm{X}$ & $X$ & $X$ & & & & & & & \\
\hline Catching the ball & From the spot & & & & & $X$ & $\mathrm{X}$ & $\mathrm{X}$ & $\mathrm{X}$ & $\mathrm{X}$ & $\mathrm{X}$ & $\mathrm{X}$ & $X$ \\
\hline & Running & & & & & & $\mathrm{X}$ & $X$ & $\mathrm{X}$ & $\mathrm{X}$ & $\mathrm{X}$ & $X$ & $X$ \\
\hline Passing the ball & From the spot & & & & & $X$ & $\mathrm{X}$ & $X$ & $\mathrm{X}$ & $\mathrm{X}$ & $\mathrm{X}$ & $\mathrm{X}$ & $X$ \\
\hline & Running & & & & & & $\mathrm{X}$ & $\mathrm{X}$ & $\mathrm{X}$ & $\mathrm{X}$ & $\mathrm{X}$ & $X$ & $X$ \\
\hline Changes of direction & Simple change of direction & & & & & & & & $\mathrm{X}$ & $\mathrm{X}$ & $\mathrm{X}$ & $\mathrm{X}$ & $\mathrm{X}$ \\
\hline Shot on goal & Running & & & & & $X$ & $X$ & $X$ & $X$ & $X$ & $\mathrm{X}$ & $X$ & $X$ \\
\hline & With ground support & & & & & & $\mathrm{X}$ & $X$ & $\mathrm{X}$ & $X$ & $\mathrm{X}$ & $X$ & $X$ \\
\hline & Jump & & & & & & & $\mathrm{X}$ & $\mathrm{X}$ & $\mathrm{X}$ & $\mathrm{X}$ & $\mathrm{X}$ & $\mathrm{X}$ \\
\hline Taking the ball out & Front & & & & & & & & $X$ & $X$ & $X$ & $X$ & \\
\hline of the dribble & From the side & & & & & & & & & $\mathrm{X}$ & $\mathrm{X}$ & $\mathrm{X}$ & $\mathrm{X}$ \\
\hline $\begin{array}{l}\text { Attacking the } \\
\text { opponent with the } \\
\text { ball }\end{array}$ & $\begin{array}{l}\text { Attack with one arm on the } \\
\text { throwing arm and the other on } \\
\text { the hip }\end{array}$ & & & & & & & & $\mathrm{X}$ & $\mathrm{X}$ & $\mathrm{X}$ & $\mathrm{X}$ & $X$ \\
\hline Blocking the balls & Blocking high balls & & & & & & & & & & $\mathrm{X}$ & $\mathrm{X}$ & $X$ \\
\hline
\end{tabular}


The same was done with the individual tactical actions planned to be trained at this stage. Table 4 shows the staging of the training for individual tactical actions.

Table 4. Grading the introduction of individual tactical actions in the training sessions

\begin{tabular}{|c|c|c|c|c|c|c|c|}
\hline & Year & \multicolumn{3}{|c|}{ Year III } & \multicolumn{3}{|c|}{ Year IV } \\
\hline & Step & I & II & III & I & II & III \\
\hline Attack & Direct demarcation & $\mathrm{X}$ & $\mathrm{X}$ & $\mathrm{X}$ & $\mathrm{X}$ & $\mathrm{X}$ & $\mathrm{X}$ \\
\hline & Penetration & & & & $\mathrm{X}$ & $X$ & $X$ \\
\hline Defence & Tight marking & $\mathrm{X}$ & $\mathrm{X}$ & $\mathrm{X}$ & $\mathrm{X}$ & $\mathrm{X}$ & $\mathrm{X}$ \\
\hline & Attacking the opponent in possession of the ball & & & $\mathrm{X}$ & $\mathrm{X}$ & $\mathrm{X}$ & $\mathrm{X}$ \\
\hline
\end{tabular}

So far, we have highlighted the number of hours required for training, as well as the staggering of children's training in the four years of stage I, designing a training model. Next, we will move our attention to what happens during mini-handball games, trying to make a game model. The development of a mini-handball game model has as main purpose the achievement of a control tool for coaches engaged in working with children aged between 8 and 10 years. Thus, we proposed the following game model:

- Attack

Technically

- movement on the field - running forward and backward, stopping, turning, moving with added or cross steps;

- dribbling - simple and multiple;

- catching and passing the ball while running in different planes - passing between 2 or 3 players while maintaining the movement lane;

- simple change of direction (right and left) followed by passing or goal throwing;

- goal throwing - while running and jumping.

Individual tactics

- catching the ball while moving towards the goal;

- direct demarcation.

The attack game does not take place in game phases and we do not have positions in the attack.

- Defence

Technically

- movement on the field - running forward and backward, stopping, turning, moving with added or cross steps;

- removing the ball from dribbling - front, side and back;

- blocking the balls thrown at the goal - high.

Individual tactics

- placement between the opponent and the own goal;

- interception of the ball;

- attacking the direct opponent;

- tight marking.

We do not have positions in defence either and we propose the "man-to-man" form of defence with half-field application. 


\section{Data}

Because the four teams targeted by our study did not play an equal number of games, after collecting the data, the actions were averaged for each player so that they could be compared. These data were entered in the formulas of the coefficients taken into account (Table 5, Figure 1).

Table 5. Data obtained from the calculation of coefficients

\begin{tabular}{|c|c|c|c|c|c|c|c|}
\hline Team & $\begin{array}{l}\text { Statistical } \\
\text { indicators }\end{array}$ & CI & $\mathrm{CM}$ & CA & $\mathrm{CE}$ & $\mathrm{CC}$ & $\mathrm{IE}$ \\
\hline $\begin{array}{l}\text { Team } 1 \\
38 \text { games }\end{array}$ & Average & 1.92 & 3.39 & 3.56 & 1.61 & 1.59 & 12.07 \\
\hline $\begin{array}{l}\text { Team } 2 \\
27 \text { games }\end{array}$ & Average & 1.48 & 2.63 & 2.15 & 0.81 & 0.72 & 7.79 \\
\hline $\begin{array}{l}\text { Team } 3 \\
32 \text { games }\end{array}$ & Average & 1.26 & 1.98 & 2.23 & 0.78 & 0.84 & 7.08 \\
\hline $\begin{array}{l}\text { Team } 4 \\
27 \text { games }\end{array}$ & Average & 1.67 & 2.96 & 3.12 & 1.41 & 1.12 & 10.18 \\
\hline
\end{tabular}

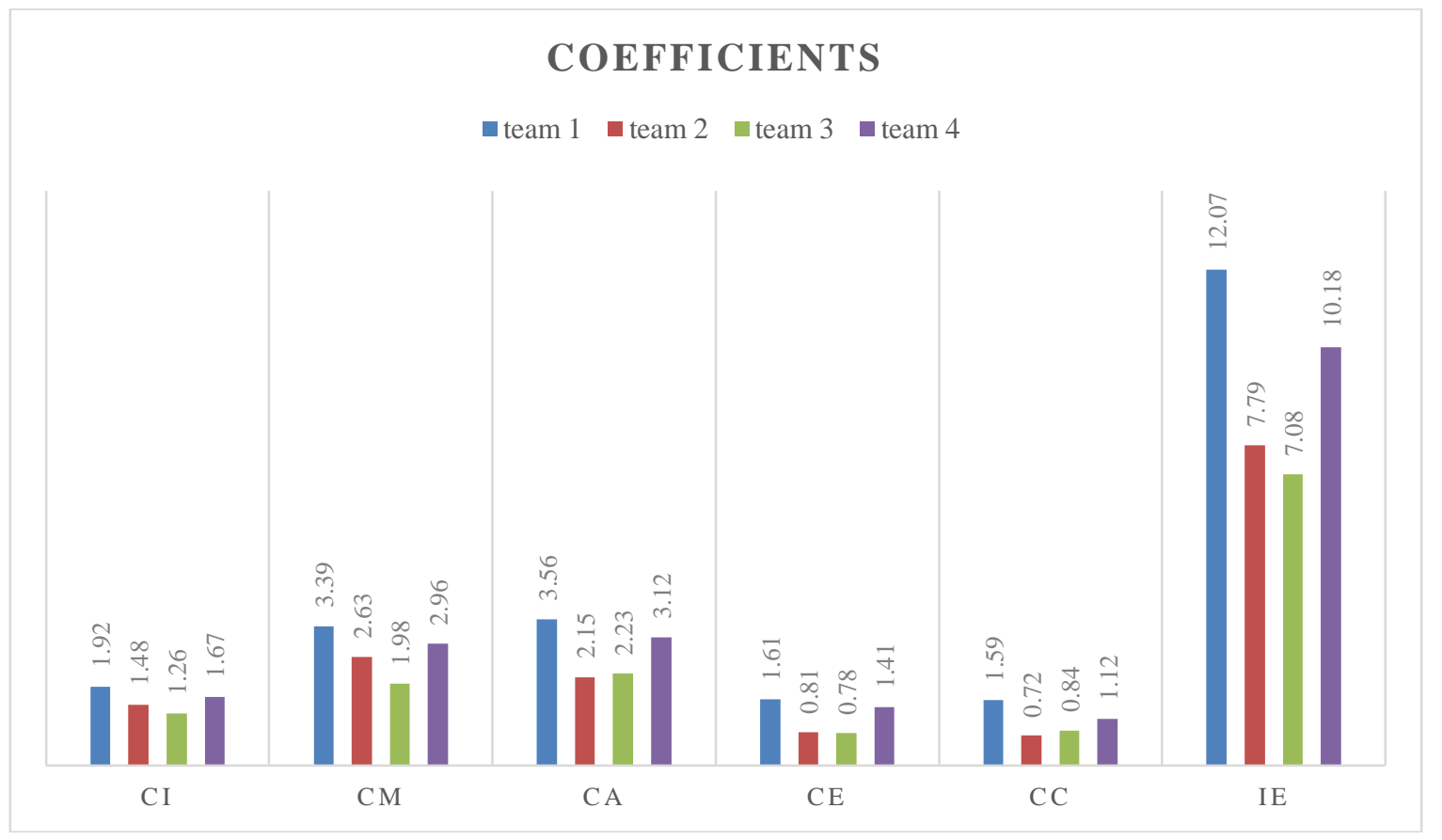

Figure 1. Values of the coefficients obtained by the four teams

\section{Discussion}

The intensity coefficient indicates the number of actions performed by a team in the unit of time. In the case of mini-handball games, the playing time is two halves of 15 minutes, so the time taken into account is 30 minutes. From the obtained data, we observe that the largest number of actions in the unit of time is performed by team 1, followed by teams 4, 2 and 3 .

The coefficient of mobility indicates the number of actions performed in motion in the unit of time. The order of the teams is the same for this indicator. 
The coefficient of aggression indicates the number of actions in motion and in direct combat with the opponent performed by a team in the unit of time. For this indicator, the order is: team 1 , team 4 , team 3 and team 2.

The coefficient of efficiency is the ratio between the total actions performed by a team and the total actions in motion in combat with the opponent. The higher this indicator, the better we realise if the players of a team manage to avoid contacts with opponents. The order for this coefficient is: team 1 , team 4 , team 2 and team 4 .

The coefficient of creativity indicates the number of actions that lead to a goal in the unit of time. For this coefficient, the order is: team 1, team 4 , team 3 and team 2.

The integral evaluation is performed by summing up the calculated coefficients. The order for this coefficient is: team 1 , team 4 , team 2 and team 3 .

Also based on the results obtained from video analysis, we can discuss the performance of a team from other points of view. The results of the analysis generate statistics that can give us a real picture of the content and efficiency of the game. Data obtained from recordings are divided into two categories: team data and player data.

\section{Team data}

Table 6. Passes and possession of the ball

\begin{tabular}{|c|c|c|c|c|c|c|c|c|c|}
\hline \multicolumn{5}{|c|}{ Passes } & \multicolumn{5}{|c|}{ Possession of the ball } \\
\hline Total & $\begin{array}{l}\text { Wrong } \\
\text { passes }\end{array}$ & $\begin{array}{l}\text { Sharp } \\
\text { passes }\end{array}$ & Behind & $\begin{array}{l}\text { In } \\
\text { front }\end{array}$ & Time & Moments & $0-5 \mathrm{~s}$ & $5-15 \mathrm{~s}$ & $15-45 \mathrm{~s}$ \\
\hline 104 & 23 & 14 & 11 & 70 & $5,30 "$ & 50 & 26 & 22 & 2 \\
\hline
\end{tabular}

These data represent, in fact, the average achieved by the observed teams (Table 6). There are games in which a team has values higher or lower than those presented, but these values revolve around the data presented above.

From the point of view of passes, we can say the following:

- during a game, the number of passes is average because, at this age, children prefer to move on the field using a lot of dribbling; if dribbling is eliminated, the number of passes will automatically increase;

- almost a quarter of the number of passes executed during the game are wrong passes (here, both the mistakes in sending the ball and those in receiving the ball are taken into account);

- one tenth of the passes are back passes, this being explained by the fact that players either do not demarcate themselves enough to receive the ball or, for safety, prefer a back pass;

From the point of view of ball possession, we can say the following:

- although the playing time is short (2 $\times 15 \mathrm{~min})$, the number of possessions for a team is very high;

- it is observed that short possessions (0-5 s and 5-15 s) are majority, while longer possessions (15-45 s) are very few; this is explained by the fact that many mistakes are made during the game that lead to the loss of ball possession or by the fact that players rush to complete the attack by throwing; 
- although the number of possessions is high, the total time of ball possession by a team is only one-sixth of the duration of the game; the reasons are the same as those set out above, but also the fact that, during the game, there are many downtimes in which referees make corrections or explain regulation issues;

- increasing the ball possession time can be achieved by eliminating mistakes, tempering children in terms of throws and better knowing the rules of the game.

Table 7. Contacts with the opponent, throws, fouls and free throws

\begin{tabular}{|c|c|c|c|c|c|c|c|c|c|}
\hline \multicolumn{4}{|c|}{ Contacts with the opponent } & \multicolumn{4}{|c|}{ Throws } & \multirow[t]{2}{*}{ Fouls } & \multirow{2}{*}{$\begin{array}{c}\text { Free } \\
\text { throws }\end{array}$} \\
\hline Defensive & Won $\%$ & Offensive & Won \% & Total & Goal & On goal & Out & & \\
\hline 32 & $29 \%$ & 31 & $71 \%$ & 23 & 8 & 18 & 5 & 20 & 20 \\
\hline
\end{tabular}

The number of contacts in attack and defence is relatively equal, but it is observed that the number of duels won in attack $(71 \%)$ is higher than in duels won in defence (29\%). This is explained by the fact that, at this age, children are more concerned with attacking play than defence. The number of fouls can also be discussed here. All fouls are committed in defence, there are no fouls in attack. This is due to the fact that the training for the defence game is at the beginning, therefore is not focused on it at this age level. (Table 7)

\section{Player data}

Table 8. Data on the attacking game

\begin{tabular}{ccccccc}
\hline $\begin{array}{c}\text { Touching the } \\
\text { ball }\end{array}$ & Passes & Throws & Goals & \multicolumn{2}{c}{ Duels in attack } & \multirow{2}{*}{$\begin{array}{c}\text { Fouls } \\
\text { suffered }\end{array}$} \\
\hline 23 & 12 & 4 & & Total & Won & 2 \\
\hline
\end{tabular}

Table 9. Defence and other data

\begin{tabular}{ccccc}
\hline \multirow{2}{*}{ Game time $(\min )$} & Actions & \multicolumn{2}{c}{ Duels in defence } & \multirow{2}{*}{ Faults committed } \\
\cline { 2 - 4 } & & Total & Won & 3 \\
\hline 18 & 8 & 5 & 2 & 3 \\
\hline
\end{tabular}

From the point of view of throws, we can say the following: out of the total number of throws (23), only 8 are converted into a goal. The efficiency of goal throws is $34.8 \%$; if we relate the number of goals to the moments of possession, then the efficiency in attack is even lower (16\%); the explanation for this is simple: children try to throw quickly at the goal without preparing enough the moment of execution of the throw and the throw. (Tables 8 and 9)

\section{Conclusion}

Mini-handball is a form of handball customised to the anatomical, physiological, psychological and motor characteristics of children aged 6 to 10 years. This form of handball is, in fact, the first step towards high-performance handball. The time required for a child to reach performance handball is 12 years. These 12 years are divided into three groups of 4 years 
each, called stages. This division into four-year groups mainly takes into account the stages of child development. Thus, stage I is associated with young school age, stage II is associated with middle school age, and stage III is associated with adolescence.

Normally, each stage has different objectives that are successively fulfilled, which leads to developing the final game model, that of high-performance handball. As a result, each stage represents a step, and at the end of each stage, the child/athlete should integrate into a game and player model corresponding to the completed stage. The development of the game model is a very important step towards achieving training efficiency, which means that all participating students should exceed the minimum-acceptable level of performance in accordance with their individual learning opportunities, in conditions of mental comfort and while saving effort and time (Jinga \& Negreț, 1994).

The analysis of competitive activity specific to handball teams has to be based on the following aspects:

- the analysis of the competitive activity of the players should not be limited only to the quantitative and qualitative analysis of their actions but also on the way and the moment in which they are performed;

- the whole training should be done gradually so that each action passes successively through the three types of complexity $(\mathrm{C} 1, \mathrm{C} 2$ and $\mathrm{C} 3)$ and therefore, when competing, the athlete must have great ease of expression during the game.

The training models allow the design of an effective training programme, which in turn allows us to rationally use the time allocated to the team training, to focus on the preponderant actions during the game and carry out training sessions adapted to the needs of the competition.

\section{References}

Allinger, T. (1998). Coaches learn to use video analysis. https://www.sportsci.org/news/biomech/video/video.html

Bilge, M. (2012). Game analysis of Olympic, World and European Championships in Men's Handball. Journal of Human Kinetics, 35, 109-118. https://dx.doi.org/10.2478\%2Fv10078-012-0084-7

Czerwinski, J. (1998). Men's Handball European Championship. Statistical analysis of the Men's European Championship. Handball - Periodical for Coaches, Referees and Lecturers, 2, 26-35.

Ferrari, W., Vaz, V., Sousa, T., Couceiro, M., \& Dias, G. (2018). Comparative analysis of the performance of the winning teams of the Handball World Championship: Senior and junior levels. International Journal of Sports Science, 8(2), 43-49. doi: $10.5923 /$ j.sports.20180802.01

Gutiérrez, M., Rojas, J., Ortega, M., Campos, J., \& Parraga, J. (2011). Anticipatory strategies of team-handball goalkeepers. Journal of Sports Sciences, 29(12), 1321-1328. https://doi.org/10.1080/02640414.2011.591421

Hantău, C. (2017). Minihandbal: Stadiul I al instruirii în handbal [Mini-handball: Stage 1 of handball training]. București: Printech.

Jinga, I., \& Negreț, I. (1994). Învățarea eficientă [Efficient learning]. București: Editis. 
Kostiukevych, V., Imas, Y., Borysova, O., Dutchak, M., Shynkaruk, O., Kogut, I., Voronova, V., Shlonska, O., \& Stasiuk, I. (2018). Modeling of the athletic training process in team sports during an annual macrocycle. Journal of Physical Education and Sport, 18(Supplement issue 1), 327-334. DOI: 10.7752/jpes.2018.s144

Kunst-Ghermănescu, I. (1976). Traité de base pour entraîneurs [Basic book for coaches]. École Internationale de Handball de Fribourg.

Morton, R. H. (1997). Modeling training and overtraining. Journal of Sports Sciences, 15(3), 335-340. https://doi.org/10.1080/026404197367344

Müller, E. \& Lorenz, H. (1996). Computergestütztes Spielanalysesystem im Spitzenfußball [Computerized game analysis system in top football]. Leistungssport, 26(1), 59-62.

Platonov, N. V. (1996). Allenamento sportive: Teoria e metodologia [Sport training: Theory and methodology]. Perugia: Calzetti Mariucci Editori.

Platonov, N. V. (2004). L'organizzazione dell'allenamento e dell'attivita di gara [Organizing training and competition activities]. Perugia: Calzetti Mariucci Editori.

Prieto, J., Gomez, M. A., \& Sampaio, J. (2015). From a static to a dynamic perspective in handball match analysis: A systematic review. The Open Sports Sciences Journal, 8, 25-34. http://dx.doi.org/10.2174/1875399X01508010025

Saavedra, J. M., Aguilar, M. P., Jimenez, F., Lozano, D., \& Kristjánsdóttir, H. (2019). Relationship between game-related statistics in elite men's beach handball and the final result: A classification tree approach. International Journal of Performance Analysis in Sport, 19(4), 584-594. https://doi.org/10.1080/24748668.2019.1642040

Sani, M. H. M., \& Khan, T. K. A. (2018). Modeling technique: The effect on rugby sport performance. International Journal of Academic Research in Business and Social Sciences, 7(10), 419-425. https://doi.org/10.6007/IJARBSS\%2FV7-I10\%2F3389

Taborsky, F. (2000). The method of quantitative evaluation of game performance in handball. Handball - Periodical for Coaches, Referees and Lecturers, 1, 55-57.

Trout, J. (2013). Digital movement analysis in physical education. Journal of Physical Education, Recreation \& Dance, 84(7), 47-50. https://doi.org/10.1080/07303084.2013.818394

Winkler, W. \& Freibichler, H. (1991). Leistungsdiagnostik beim Fußballspiel [Performance diagnosis of a football match]. Leistungssport, 21(2), 25-31.

Zapardiel Cortés, J. C., Ferragut, C., Manchado, C., Abraldes, J. A., \& Vila, H. (2017). Difference of the speed of handball throwing during the competition in relation to efficiency: Analysis between the first and the second half. Journal of Human Sport \& Exercise, 12(3)., S872-881. https://doi.org/10.14198/JHSE.2017.12.PROC3.11

Zemkova, E., \& Hamar, D. (2018). Sport-specific assessment of the effectiveness of neuromuscular training in young athletes. Frontiers in Physiology, 9: 264.

https://doi.org/10.3389/fphys.2018.00264 